\title{
An assessment of nursing mothers' and young people's access to proprietary and patent medicine vendors' services in rural communities of south-eastern Nigeria: implication for review of national drug policy
}

\author{
C. J. Uneke* (D, I. Obeka, B. I. Uneke, A. Umeokonkwo, C. A. Nweze, K. I. Otubo and O. E. Uguru
}

\begin{abstract}
Background: Patent and proprietary medicine vendors (PPMVs) form part of the informal healthcare system and are the first point of call for $75 \%$ of Nigerians who live in rural and underserved areas where there is limited access to healthcare services. This group of healthcare providers are located close to communities and are easily accessible to the people. This study seeks to determine how PPMVs influence access to medicines among nursing mothers and young people and how this progresses South Eastern Nigeria towards universal health coverage.

Methods: A cross-sectional descriptive study was conducted using a purposive sampling technique. Two slightly different pre-tested and validated 5-point Likert scale questionnaires were used to survey the nursing mothers and young people (18-20 years old). The questionnaire for nursing mothers assessed the perception regarding PPMV services and community access to medicines used for the treatment of childhood infections. The questionnaire for young people assessed the services rendered by the PPMVs including family planning, and major enablers/barriers towards to access to medicine.
\end{abstract}

Results: A total of 159 nursing mothers and 148 youths participated in the study. Up to 60\% of both population had a minimum of secondary school qualification. About $90 \%$ of the nursing mothers were married and $88 \%$ were nursing babies from 1 to 12 months. Results show that the PPMVs were the first point of call for healthcare needs among the respondents and they are easily accessible and sell affordable medicines. The nursing mothers frequently treat their children's cough with antibiotics with a mean rating (MNR) of 4.7 out of 5 points and most source these antibiotics from PPMV shops. Up to $90 \%$ of the nursing mothers reported that the children got well after the treatment. The drugs mostly purchased by the youths from the PPMVs included antimalarials (95\%), analgesics (87.7\%) and antibiotics (81.3\%). Only $25.5 \%$ of the respondents purchased family planning commodities. Most of the respondents sought health care from PPMVs with a MNR of 3.4. Patronage of PPMVs for and usage of family planning products by the respondents had MNRs ranging from 1.4 to 1.8 .

*Correspondence: unekecj@yahoo.com

African Institute for Health Policy \& Health Systems, Ebonyi State

University, PMB 053, Abakaliki, Nigeria original author(s) and the source, provide a link to the Creative Commons licence, and indicate if changes were made. The images or other third party material in this article are included in the article's Creative Commons licence, unless indicated otherwise in a credit line to the material. If material is not included in the article's Creative Commons licence and your intended use is not permitted by statutory regulation or exceeds the permitted use, you will need to obtain permission directly from the copyright holder. To view a copy of this licence, visit http://creativecommons.org/licenses/by/4.0/. The Creative Commons Public Domain Dedication waiver (http://creativeco mmons.org/publicdomain/zero/1.0/) applies to the data made available in this article, unless otherwise stated in a credit line to the data. 
Conclusion: PPMVs are bridging the gap in healthcare delivery in the rural and underserved areas. Training of this group of practitioners and appropriate monitoring will go a long way in ensuring that the services they render are efficient, effective and improve the health indices in a low-income setting.

\section{Introduction}

Within the last decade, child health outcomes in Nigeria have somewhat improved, but the current situation is still unacceptably poor, especially in rural areas where health services are inadequate or completely lacking. With a population of more than 200 million, Nigeria has about $2.5 \%$ of the population of the world and $10 \%$ of all under-five deaths, translating into more than 1 million newborn, infant, and child deaths annually [1]. Maternal mortality ratio is estimated at 512 maternal deaths per 100,000 live births, and pregnancy-related mortality ratio is estimated at 556 pregnancy-related deaths per 100,000 live births [1]. Under-5 mortality rate is estimated at 132 deaths per 1000 live births, while infant mortality rate is estimated at 67 deaths per 1000 live births [1,2]. This implies that more than 1 in 8 children in Nigeria die before their 5 th birthday. Adult mortality rate is 3.18 deaths per 1000 population among women, and lifetime risk of maternal death indicates that one in 34 women in Nigeria will have a death related to maternal causes $[1,3]$. Available reports indicate that Nigeria loses 2300 under-5 year olds every day, making the country the second largest contributor to under-five mortality in the world [3]. Another report showed that more than a quarter of a million neonates die in Nigeria each year, representing about 700 neonates per day [4]. It is important to state that most of these deaths are preventable, but the rural communities bear the greatest burden because of lack of timely access to medicines and healthcare.

According to the World Bank and United Nations Population Fund, of the estimated Nigeria population of $200,963,599$ in 2019 , about $22 \%$ (44.2 million) of the people are adolescents $[5,6]$. The majority of this very high number of adolescents reside in rural areas. The lives of these young people are characterized by challenges in maintaining basic health and accessing health services, violence and abuse, dangerous behavioural activities due to peer pressure and difficult working conditions, all of which can negatively impact their health [7].

The Nigerian population is predominantly rural with over $75 \%$ of the population dwelling in rural areas where access to healthcare services provided by the formal sector are limited [8-10]. Consequently, the proprietary and patent medicine vendors (PPMVs), defined as individuals who have not received formal training in pharmacy but authorized to sell orthodox pharmaceutical products on a retail basis for profit $[8,9]$, are an important source of health care services. PPMVs shops are found in nearly all communities in Nigeria and are often the first and sometimes the only source of health care in those localities. They are the main access points for a range of health commodities and services, and are sought out for health advice and diagnosis, particularly amongst poor and rural populations with limited access to formal health services [10].

Available reports indicate that most young people in Nigeria, choose to patronize PPMVs over other services. The reasons are because the majority of young people cannot afford the very expensive private hospitals and clinics with professional staff and standardized services and also, they are unwilling to tolerate long waits, bureaucracies and costs at government-managed hospitals, which are currently understaffed and underresourced [11].

An estimated 200,000 PPMVs operated in the country as of 2005, far outnumbering the 2639 retail pharmacies that were registered in the same year, and more than all other cadres of health workers in the country [12]. Unlike pharmacies which tend to be geographically concentrated in urban areas, PPMVs are more distributed across sub-urban and rural areas [13]. National surveys show that PPMVs are the first source of care for $55 \%$ of cases of fever, $30 \%$ of cases of diarrhoea, and $8 \%$ of cases of cough occurring amongst children under five [14]. Communityand state-level studies of care-seeking behaviour similarly find that PPMVs are the first source of care for up to 55\% of under-five child illnesses, and provide services for 35\% to $55 \%$ of adults seeking malaria treatment and remains the most preferred service by the poor $[10,15]$.

Due to the large numbers of PPMVs and their presence in rural areas, there are obviously regulatory challenges. However, policymakers and programme implementers in Nigeria are increasingly recognizing the need to engage PPMVs in a more efficient manner so they can contribute to the delivery of basic healthcare commodities and services to rural dwellers [10]. The Nigeria Drug Law Policy permits PPMVs to sell a limited number of pre-packaged, over-the-counter medicines and medical products to consumers, but prohibits the PPMVs from selling drugs categorized as prescription medications (e.g. antibiotics) and conduct medical procedure classified as invasive (e.g. injections) [16]. But it is in the recognition of the vital role of the PPMVs that is demonstrated by the fact that a number of Nigerian health policies and regulatory 
changes included them as important healthcare service providers especially in places where the formal sector cannot reach. For instance, following the revision of the national treatment guidelines for uncomplicated malaria with the recommendation of artemisinin-based combination therapy (ACTs) as the first-line treatment, the List of Essential Medicines was revised to authorize the PPMVs to sell ACTs [16].

The Nigerian Government has also approved the addition of paediatric zinc and co-packaged zinc and oral rehydration salts (ORS) to PPMVs' list of approved medications as part of the national Essential Medicines ScaleUp Plan (EMSUP) [10]. Also included in the EMSUP is the implementation of continuous education and other forms of capacity development for PPMVs to improve their quality of care for common childhood illness [17]. PPMVs have also been listed as potential communitylevel implementers for the newly adopted national integrated Community Case Management (iCCM) guidelines [18], and have been included in a pilot project for home management of malaria under the National Malaria Strategic Plan [19]. The National Task Shifting and Sharing Policy issued in 2014 also calls for capacity building of community-oriented resource persons, including PPMVs, to provide treatment, counseling, and referral for some child health services [10].

In recent times there have been calls for more policy change to expand the scope of operations of the PPMVs to accommodate more services related to childhood illnesses and access to medicines by adolescents, but more evidence is needed to determine the safety and feasibility of this practice. In this study we assessed youths' and nursing mothers' access to PPMVs' services, to provide scientific evidence that can guide possible policy change.

\section{Methods}

\section{Study area}

The study was conducted in Ebonyi State, south-eastern Nigeria. It is made up of 13 Local Government Areas (LGAs) divided into three senatorial-zones (North, Central, South), which are geopolitical zones designed to facilitate equity in resource allocation. The population of the State was put at $2,176,947$ by the 2006 census. The 2018 population projected from 2006 census with a growth rate of $2.8 \%$ was $3,053,607$ (48.9\% males and $51.1 \%$ females). The average population density is 386 persons per square kilometre. Women of child bearing age (WCBA) (15-49 years) constitute $22 \%$ of the total population [9]. Besides very few semi-urban towns, all other areas are predominantly rural with about $75 \%$ of the population living in the rural and underserved communities and are predominantly farmers and traders.
According to the Ebonyi State Ministry of Health [9], major causes of infant and under-5 morbidity and mortality include: neonatal causes (26\%), malaria (24\%), pneumonia (20\%), diarrhoea (16\%), measles (6\%), HIV/ AIDS (5\%) and others (3\%). Most of these deaths occur in the rural areas where the formal healthcare services are lacking. Consequently, there is a large number of the informal providers in the private healthcare sector, and in particular owner-operated drug shops called patent and proprietary medicine vendors (PPMVs) operating in these rural communities. These PPMVs are the major sources of healthcare services in these rural communities of Ebonyi State. Three LGAs have been selected for the study with one from each senatorial zone: North (Izzi); Central (Ikwo); South (Ohaozara).

\section{Study design}

The study design was a cross-sectional descriptive study technique. The participants included young people and nursing mothers.

\section{Survey of nursing mothers}

A 5-point Likert scale structured questionnaire was developed and pre-tested in another LGA and validated. This enabled us to adjust the tool to optimize data collection. The development, pretesting, and validation of the questionnaire were done using the methods described by Tsang and colleagues [20]. First, a thorough consideration of issues relating to the format of the questionnaire and the meaning and appropriateness of the items were considered during the questionnaire development stage. Thereafter, a pilot test (undeclared pretest) was conducted on a limited number of respondents to ensure that the items were understood and correctly interpreted by the intended respondents. The questionnaire validation was done to ensure its reliability and that it was sound psychometrically. The questionnaire assessed the perception of the nursing mothers regarding PPMV services and community access to medicines, where they obtained them, what type of medicines they use for the treatment of childhood cough/acute respiratory infections, sources of advice/information on the treatment of coughs and colds and on the use of antibiotics, and type of advice the PPMVs give on treatment of coughs and cold for their children.

The inclusion criteria were as follows: (i) respondent must be a nursing mother; (ii) must been residing in the target LGAs for at least 6 months; and (iii) must have used the services of the PPMVs.

The nursing mothers were selected for this study because they are the care givers in their families and are usually the ones to seek medical attention for their children at the PPMVs shops. Nursing mothers attending 
immunization clinic at the government Primary Healthcare Centre (PHC) in each of the LGAs, were randomly recruited for the survey. Approval was obtained from the Executive Secretary of the Primary Healthcare Development Agency of the Ebonyi State and from the medical officer-in-charge of each of the target PHCs in the LGAs.

On each of the days of the survey, before the commencement of the immunization activities at the PHCs by the nurses, members of the research team were granted the opportunity to address the nursing mothers, introduced the study to them and invited them to participate. Consenting nursing mothers were administered with the questionnaire privately. Before giving any one the questionnaire, oral informed consent was obtained. We used part of the waiting time (maximum $20 \mathrm{~min}$ ) of the mothers which is usually between 40 and 60 min or the time after the immunization, depending on what is most convenient for the respondent. All the mothers who could not speak English were interviewed and assisted to complete the questionnaire by members of the research team, who spoke the local language of the respondents. The research team also visited some additional nursing mothers, booked appointments with them for the survey, and at the appointed day and time at their respective homes, administered the questionnaire to them at the time most convenient to them.

\section{Survey of young people}

We targeted up to 50 young people from each of the three LGAs. The study inclusion criteria included: (i) participant must be aged 18-20 years old; (ii) participant must be residing in the target LGAs for at least 6 months; (iii) participant must have used the services of the PPMVs in the locality.

Data collection was done using a structured pre-tested questionnaire similar to the one used for the nursing mothers but with some modification. The questionnaire was designed in a 5-point Likert scale which assessed PPMV services and access to medicines including family planning services and major enablers and barriers to access to services rendered by PPMVs. Other questions to youth explored commonest clinical presentations to PPMVs, commonly used medications, major sources of health advice/information, experience after accessing medicines from PPMVs, and cost of medicines from PPMVs.

A purposive sampling technique was used to identify consenting and willing participants. The researchers met participants in the streets and market places. The questionnaire was administered to each of the youths privately having assured each of them that information obtained was for research purposes and that confidentially of information given would be maintained. The questionnaire was administered by trained research assistants who were young and within the age bracket of the respondents to allow for easy interaction. The questionnaire was self-administered, but was interviewer administered if the subject was not literate. Written informed consent was obtained from each of the respondents and oral consent from the non-literate respondents. Maximum duration for the engagement per person was $20 \mathrm{~min}$.

\section{Data analysis}

Analysis of data collected via the 5-point Likert scale questionnaire was done using the methods developed at McMaster University Canada by Johnson and Lavis based on mean ratings (MNRs) [21]. For instance, the figures represent Likert rating scale of $1-5$ points, where 1 point $=$ grossly inadequate; 2 points $=$ inadequate; 3 points $=$ fairly adequate; and 5 points $=$ very adequate. In terms of analysis, MNR ranging from 1.00 to 3.49 points were considered low, whereas MNR ranging from 3.50 to 5.00 points were considered high [22].

\section{Ethical approval}

Ethical clearance was obtained from the University Research Ethics Committee (UREC) of Ebonyi State University Abakaliki (Ref: EBSU/DRIC/UREC/Vol. 05/047) and the Ethics Review Committee of the World Health Organization. Both the institutional and international guidelines on research ethics were strictly adhered to in all aspects of the project. Participant anonymity was maintained and all findings were treated with utmost confidentiality and for the purpose of the research only.

\section{Results}

\section{Outcome of assessment of nursing mothers}

A total of 159 nursing mothers (54 in Ohaozara LGA, 53 in Ikwo LGA, and 52 in Izzi LGA), participated in this study. Up to $62 \%$ of the nursing mothers were aged 21-30 years, had secondary education (60.56\%), traders (46.3\%), and had 1-2 children (41.1\%). Most of the mothers $(90.3 \%)$ were married and up to $69.7 \%$ of the respondents had lived in the community for upwards of 10 years. The age of the babies most of respondents were nursing was in the range of 1 month to 5 months (Table 1 ).

The outcome of the nursing mothers' perception of the PPMV services and community access to medicines is shown in Table 2. The MNRs for questions related to PPMVs being the first and often the only point of call for health care services; PPMVs being easily accessible; and PPMVs selling cheaper and more affordable drugs ranged from 3.2 to 3.6 on the scale of 5 points (Table 2). For the questions related to PPMVs sale of low quality, expired or sub-standard drugs; PPMVs not having the 
Table 1 Socio-demographic characteristics of the respondent nursing mothers in rural areas of Ebonyi State Nigeria

\begin{tabular}{|c|c|c|}
\hline Characteristics & Frequency & Percent \\
\hline \multicolumn{3}{|l|}{ Age (years) } \\
\hline$\leq 20$ & 14 & 8.9 \\
\hline $21-30$ & 98 & 62 \\
\hline $31-40$ & 41 & 26 \\
\hline $41-50$ & 5 & 3.2 \\
\hline Total & 158 & \\
\hline \multicolumn{3}{|l|}{ Marital status } \\
\hline Single & 14 & 9.0 \\
\hline Married & 140 & 90.3 \\
\hline Widow/widower & 1 & 0.6 \\
\hline Total & 155 & \\
\hline \multicolumn{3}{|l|}{ Education } \\
\hline No formal & 2 & 1.3 \\
\hline Primary & 38 & 24.5 \\
\hline Secondary & 94 & 60.6 \\
\hline Tertiary & 21 & 13.5 \\
\hline Total & 155 & \\
\hline \multicolumn{3}{|l|}{ Occupation } \\
\hline Student & 2 & 1.6 \\
\hline Unemployed & 16 & 13 \\
\hline Civil servant & 18 & 14.6 \\
\hline Trader & 57 & 46.3 \\
\hline Farmer & 26 & 21.1 \\
\hline Hand craft & 34 & 27.6 \\
\hline Total & 123 & \\
\hline \multicolumn{3}{|c|}{ How many children you have } \\
\hline $1-2$ & 65 & 41.1 \\
\hline $3-4$ & 45 & 28.5 \\
\hline $5-6$ & 33 & 20.9 \\
\hline$\geq 7$ & 15 & 9.5 \\
\hline Total & 158 & \\
\hline \multicolumn{3}{|c|}{ How old is present child nursed } \\
\hline $1-5$ months & 90 & 57 \\
\hline $6-12$ months & 49 & 31 \\
\hline 13-18 months & 14 & 8.9 \\
\hline$\geq 19$ months & 5 & 3.2 \\
\hline Total & 158 & \\
\hline \multicolumn{3}{|c|}{ Duration of residency in the community (years) } \\
\hline $1-3$ & 18 & 11.8 \\
\hline $4-6$ & 19 & 12.5 \\
\hline $7-9$ & 9 & 5.9 \\
\hline$\geq 10$ & 106 & 69.7 \\
\hline Total & 152 & \\
\hline
\end{tabular}

prerequisite training to operate shops, sale of medicines without prescription; and PPMVs having low health knowledge about proper treatment for common illnesses, the recorded MNR ranged from 3.3 to 3.8 (Table 2). In terms of the frequency of treatment of children's coughs and colds with antibiotics in self-care (without consulting a health worker) by the mothers, the MNR recorded was 4.7. The MNR for their perceived efficacy of antibiotics and awareness of risks of antibiotics was 4.0 (Table 2).

Up to $31.3 \%$ of the respondents credited their knowledge of drugs to PPMVs, while $57.1 \%$ of them accepted that the antibiotics they used in self-care were obtained from patent medicine stores or chemists (Table 3). Finding showed that $36.6 \%$ of the respondents commenced treatment on childhood acute respiratory infections (cough/cold) within $1 \mathrm{~h}$ of noticing the sickness, while $55 \%$ of the respondents noted that they administered antibiotics three times a day and $42 \%$ administered the antibiotics for 3 days. More than $90 \%$ of the respondents' children got well as a result of administration of the antibiotics. Up to $65.5 \%$ of the mothers did not have to take their children to a health facility after treatment at home. Of the number that took their children to hospital $68.6 \%$ did so to ensure that the child is cured. Up to $46.4 \%$ of the respondents who agreed that they used non-drug therapy used herbs/herbal mixtures for treatment of their children (Table 3).

\section{Outcome of assessment of youths}

A total of 148 youths participated in the study (53 in Ohaozara LGA, 46 in Ikwo LGA, and 49 in Izzi LGA). More than a third (44\%) of the respondents were in their 20 years of age. $52.4 \%$ of the respondents were female and $60 \%$ had a secondary education. Fifteen percent of the respondents were married. Seventy percent of the respondents had lived more than 10 years in the study areas. More than half of the respondents lived with their parents (Table 4).

In terms of how often the respondents go to various sources of treatment for illness, the source with the highest MNR was PPMVs (3.4), followed by hospital (2.5) and health centre (2.4). The PPMVs being easily accessible to rural communities had MNR of 4.2 followed by discouraging dispensing medicine without prescription which had MNR of 4.0. Medicine availability without restriction being a big problem recorded MNR of 3.9, while MNR of 3.7 was recorded for PPMVs being the first and often the only point of care in rural area and sale of cheaper and affordable (Table 5). Patronage of PPMVs and usage of family planning products and sexually transmitted disease medications by the respondents had MNRs ranging from 1.4 to 1.8. Access to abortion or post-abortion care from the PPMVs by the female respondents had MNR of 1.4 (Table 5).

The drugs mostly purchased by the youths from the PPMVs included antimalarials (95\%), analgesics (87.7\%), antibiotics (81.3\%), antiseptics (72.4\%), haematinics 
Table 2 Nursing mothers' perception of the PPMV services and community access to medicines in rural areas of Ebonyi State Nigeria

\begin{tabular}{lc}
\hline To what extent do you agree with the following (strongly disagree, disagree, unsure, agree, strongly agree) & $\begin{array}{c}\text { Mean rating (out of } \\
\text { 5-point Likert scale) }\end{array}$ \\
\hline (i) PPMVs are the first and often the only point of call for health care services in this rural area & 3.2 \\
(ii) PPMVs are easily accessible to the rural dwellers & 3.3 \\
(iii) The medicines and drugs sold by the PPMVs are cheaper and more affordable than in hospitals and pharmacies & 3.6 \\
(iv) Many PPMVs in this locality sell low quality, expired or sub-standard drug to the rural dwellers & 3.3 \\
(v) Many of the PPMVs in this locality do not have the prerequisite training to operate PPMV shops & 3.3 \\
(vi) Sale of medicines without prescription is rampant in this locality & 3.8 \\
(vii) PPMV shop owners and operators generally have low health knowledge about proper treatment for common illnesses, such & 3.5 \\
as cough, malaria and diarrhoea and poor health treatment practices & 4.7 \\
Frequency of treatment with antibiotics (never, rarely, occasionally, frequently, very frequently) \\
How frequent do you treat your children's coughs and colds with antibiotics in self-care (without consulting a health worker) \\
Effectiveness of treatment with antibiotics (don't know, not effective, fairly effective, effective, very effective) \\
How would you describe the effectiveness of these other treatments as compared to antibiotics? \\
Perceived efficacy of antibiotics and awareness of risks of antibiotics (grossly inadequate, inadequate, fairly adequate, adequate, very adequate) \\
What is your perceived efficacy of antibiotics? \\
How adequate is your level of awareness of risks of antibiotics?
\end{tabular}

(66.9\%), and oral rehydration solution (62.8\%). Only 37 (25.5\%) of the respondents purchased family planning products (Table 6). Geographical proximity, low cost of medicine and good response (i.e. symptoms resolved) to care given were the three top enablers to respondents' patronage of PPMVs. Major barriers to patronage of PPMVs were inadequate training of the PPMVs, sale of substandard/expired drugs and low educational qualification of the PPMVs (Table 6).

The common illnesses for which the respondents visited the PPMVs for treatment were malaria, headache, and stomach ache (Table 7). The two most common sources of advice or information about medicine were from parents (42.2\%) and from PPMVs (38.4\%). The commonest used medicines were antimalarial (41.1\%), paracetamol (38.4\%), analgesics (36.3\%), antibiotics (34.2\%) and contraceptives (15.8\%). A higher percentage (67.8\%) of the respondents stated their symptoms improved after accessing care from PPMVs (Table 7).

\section{Discussion}

The outcome of this study suggests that the PPMVs are the first and often the only point of call for healthcare services among nursing mothers in the rural areas and that they are easily accessed by those that live in rural areas. In Nigeria, owner-operated drug retail outlets or PPMVs are the main source of medicine for acute conditions [19]. In particular, drug shops comprise a sizeable portion (nearly $40 \%$ ) of the private healthcare sector in Nigeria and provide between 80 and $90 \%$ of all child health services in rural areas [10, 11]. Durowade and associates [23] in their study showed that majority of the clients could access PPMV shops within 2-30 min' walk and that clients could go to the PPMVs houses or call them on phone after closing hours. This study further corroborated the findings in the study conducted by Iheoma and co-workers [24] where they noted that PPMVs are accessible, affordable and are valuable sources of healthcare services, products and information.

The results also clearly suggest that the PPMVs remain the most popular source of medicine and health services among young people. The reasons for their choice of the PPMVs include geographical proximity, cheap drugs, good response to care (i.e. symptoms resolved), no delay in accessing care, good rapport with the people and access to credit facility are consistent with previous studies from Nigeria [7, 11, 25]. In addition to these enablers, Okonkwo and Okonkwo [11] added that Nigerian youths prefer PPMVs because they are more accessible to young patrons than public sector health service providers; display non-judgemental attitudes towards young people's sexual healthcare needs; they are diplomatic, confidential and offer a wide array of sexual health services to youth, despite policy regulations that constrain this.

PPMVs have played vital roles in the health care system in different parts of Nigeria. In assessing the enablers and barriers to the use of PPMVs, we found that the geographical proximity of PPMVs was a major enabler to their patronage by the young people in the study area. This finding has been corroborated by earlier studies which reported that PPMVs located in an area close to the community was a strength for their operation [11, $26,27]$. This has also been noted by PPMVs themselves as reported by Sieverding and Beyeler [26]. This finding 
Table 3 Nursing mothers' response on access to services provided by PPMVs for childhood illness treatment

Parameter assessed

Frequency Percent

Sources of advice/information on the treatment of coughs and colds and on the use of antibiotics

(a) Chemist/patent medicine vendor $\quad 52$

(b) Health worker

(c) Neighbour

(d) Family members/relatives

Others

Total

What kind of advice do the PPMVs give on treatment of coughs and cold for your child? Administer drugs including antibiotics

Sources where antibiotics used to treat childhood cough/acute respiratory infections are obtained
(a) PPMVs store
(b) Primary Health Centre
(c) General hospital
(d) Drug hawkers
(e) Others

The last time child had childhood acute respiratory infections, how many hours after noticing did you commence the treatment
(a) Within $1 \mathrm{~h}$
(b) Within 2 to $6 \mathrm{~h}$
(c) Within 6 to $12 \mathrm{~h}$
(d) Within $12 \mathrm{~h}$ to 1 day
(e) Within 1 day to 2 days
Total

How many times in a day did you administer the drug?
(a) Once
(b) Twice
(c) 3 times
(d) 4 times
(e) 5 times

Total

For how many days did you give the drug?
(a) 1 day
(b) 2 days
(c) 3 days
(d) 4 days
(e) 5 days

Total

What was the outcome of the treatment you gave your child?

(a) Got well

(b) Got a little better

Total

Did you have to take your child to a health facility, dispensary or chemist after treatment at home with the drugs? 
Table 3 (continued)

\begin{tabular}{|c|c|c|}
\hline Parameter assessed & Frequency & Percent \\
\hline Total & 149 & \\
\hline \multicolumn{3}{|l|}{ If Yes, why? } \\
\hline (a) Sickness persisted & 15 & 29.4 \\
\hline (b) To be sure child is cured & 35 & 68.6 \\
\hline (c) Sickness getting worse & 1 & 2.0 \\
\hline Total & 51 & \\
\hline \multicolumn{3}{|c|}{ What other treatments do you use (including non-drug therapies) to treat childhood cough/acute respiratory infections? } \\
\hline Herbs/herbal mixture & 58 & 46.4 \\
\hline Warm water & 51 & 40.8 \\
\hline Balm & 16 & 12.8 \\
\hline Total & 125 & \\
\hline
\end{tabular}

is important as it reflects that geographical barriers present a challenge to accessing healthcare, which is critical to address when progressing towards achieving universal health coverage. In most rural communities where there are access challenges, PPMVs fill the gaps. They are perceived as the frontline health workers in these communities, playing an important primary health care function [28]. Since the PPMVs already have some trust and rapport with the community and can provide some basic services, they can play an important role in healthcare delivery and should be considered as an integral part of Nigeria's strategy towards universal health care. They could be made more functional through proper training and regulation.

Majority of the young people in this study, affirmed that drugs sold by PPMVs were cheaper and more affordable than those in hospitals and pharmacies. This is in agreement with the study by Iheoma and co-workers [24] they acceded to the fact that drugs purchased from PPMVs are cheaper. A significant proportion of the respondents reported that the affordable cost of products and services encouraged their use of services provided by PPMVs. Similar observations have been reported earlier [27]. Financial barriers to accessing the formal health system have also been reported as reason for patronage of PPMVs, as they cannot afford services of private hospitals and clinics [19]. In this study, other enablers found, regarding the patronage of PPMVs by young people, just as the nursing mothers, were their good response to given care (resolution of symptoms) by the PPMVs, short waiting time and friendly nature of PPMVs.

The resolution of symptoms, short waiting time and friendly nature of PPMVs were reported to encourage patronage of PPMVs in previous studies [29-31]. These findings draw attention to some gaps to in the formal health system that need urgent attention. The importance of patient satisfaction to encourage accessing health services and the negative effects of prolonged waiting time on service uptake have been reported [32-34]. Similarly, the absence of health insurance coverage and the subsequent financial impact of out-of-pocket spending should be considered for their implications in achieving universal health coverage (UHC). In a bid to avoid catastrophic health spending that may result from accessing health care in the formal setting, these young people are attracted to the cheaper alternatives provided by the PPMVs.

This study showed that the nursing mothers agreed that PPMVs sell low quality medicines. This is in consonance with earlier studies which showed that nearly half of antimalarial drugs stocked in PPMV shops were sub-standard or expired $[35,36]$. PPMVs generally have low health knowledge and poor treatment practices, stock poor quality medicines (e.g. partial or repackaged doses) [37] and substandard formulations [38] as well as commodities they are prohibited to sell [39]. Sale of substandard and expired drugs by the PPMVs was also one of the barriers reported by the young people in our study. This may be related to weak enforcement of the set down guidelines and regulations by the regulatory authority [34]. The implication of this finding is that if the PPMVs are not strictly regulated and supervised, they may likely contribute to increased morbidities and mortalities attributable to use of substandard and expired drugs.

A fairly significant population of the nursing mothers felt that PPMVs in their locality do not have the prerequisite training to operate PPMV shops. They also agreed that operators generally have low health knowledge about proper treatment for common illnesses. This is so because conventionally, the minimum educational attainment stipulated by PCN for registration of PPMVs has been primary schooling [24] and Egbohin his work [40] stated that formal medical or pharmacy training is not required for PPMV licensure. Our study showed that 
Table 4 Socio-demographic characteristics of the respondent youths in rural areas of Ebonyi State Nigeria

\begin{tabular}{|c|c|c|}
\hline Characteristics & Frequency & Percent \\
\hline \multicolumn{3}{|l|}{ Age (years) } \\
\hline 18 & 44 & 30.4 \\
\hline 19 & 37 & 25.5 \\
\hline 20 & 64 & 44.1 \\
\hline Total & 145 & \\
\hline \multicolumn{3}{|l|}{ Sex } \\
\hline Male & 70 & 47.6 \\
\hline Female & 77 & 52.4 \\
\hline Total & 147 & \\
\hline \multicolumn{3}{|l|}{ Education } \\
\hline No formal & 1 & 0.7 \\
\hline Primary & 21 & 15.2 \\
\hline Secondary & 83 & 60.1 \\
\hline Tertiary & 33 & 23.9 \\
\hline Total & 138 & \\
\hline \multicolumn{3}{|l|}{ Marital status } \\
\hline Single & 122 & 84.1 \\
\hline Married & 22 & 15.2 \\
\hline Separated & 1 & 0.7 \\
\hline Total & 145 & \\
\hline \multicolumn{3}{|l|}{ Occupation } \\
\hline Student & 78 & 53.8 \\
\hline Hand craft & 36 & 24.8 \\
\hline Trader & 11 & 7.6 \\
\hline Unemployed & 10 & 6.9 \\
\hline Civil servant & 4 & 2.8 \\
\hline Farmer & 6 & 4.1 \\
\hline Total & 145 & \\
\hline \multicolumn{3}{|c|}{ Duration of residency in the community (years) } \\
\hline $1-3$ & 25 & 17.2 \\
\hline $4-6$ & 10 & 6.9 \\
\hline $7-9$ & 8 & 5.5 \\
\hline$\geq 10$ & 102 & 70.3 \\
\hline Total & 145 & \\
\hline \multicolumn{3}{|l|}{ Home status } \\
\hline Live alone & 19 & 12.9 \\
\hline Live with parents & 97 & 66.0 \\
\hline Living with guardians/relatives & 12 & 8.2 \\
\hline Live with spouse/co-habiting & 19 & 13 \\
\hline Total & 147 & \\
\hline
\end{tabular}

perceived lack of training of PPMV staff was one of the main barriers to seeking health care from them among youth. Despite this, youth still accessed their services, potentially due to limited availability of alternatives or financial barriers to accessing the formal health sector. This perceived lack of training of PPMV staff is supported by Oyeyemi et al. [41] who reported that only a third of PPMVs had previous health related training. Additionally, Chiaka and colleagues [29], showed that PPMVs are not knowledgeable in diagnosis and treatment of diseases.

A systematic survey carried out by Beyeler and associates [25] noted that most PPMVs have low health knowledge and poor health treatment practices. For the PPMVs to give appropriate and timely advice to caregivers who tend to the sick children, it is necessary that they have basic knowledge of the presentation, cause, treatment and prevention of childhood diarrhoea [43]. However, Liu and his workers noted that majority of shop owners they assessed in their study in parts of Nigeria, have completed secondary or post-secondary education [10]. With a significant association demonstrated between knowledge and education level, an opportunity is presented for policies and interventions that emphasize education and training of PPMVs to improve their knowledge on childhood diarrhoea (and perhaps other childhood illnesses?) and to function optimally in primary care delivery in the community $[42,43]$.

The respondents fully agreed that sale of medicines without prescription in their locality was rampant. This study validates the result of the study by Akinyandenu and colleagues [43] where they noted that the sale of antibiotics without medical prescription has been observed in many countries [39]. A study conducted in Nairobi showed that about $64 \%$ of chemists sold antibiotics without prescription [36]. Antimalarials, analgesics, antibiotics and antiseptics were the most purchased drugs from PPMVs in our study. This outcome is related to the commonly endemic illness and injuries in rural setting and has been corroborated in earlier studies [27]. It is also instructive to note that some prescription-only medications are sold by these PPMVs. This clearly points to weak regulation of these drugs.

Most nursing mothers in this study agreed that they treat their children's cough and cold with antibiotics in self-care without consulting a health worker. This is in tandem with the study which noted that $80 \%$ of illness episodes are self-treated with medicines obtained from community pharmacies [44]. This study further revealed that more than half of the respondents obtained these antibiotics used in the treatment of childhood cough and cold from PPMVs. Indalo [45] in his study showed that most chemist shops in peri-urban areas sold antibiotics without prescription.

A considerable proportion of the nursing mothers, noted that they sought for treatment of their children's cough within $1 \mathrm{~h}$ of noticing the sickness. This must have been made possible because the respondents are nursing mothers, who given their close contact with children 
Table 5 Perception of youths on the PPMV services and young people's access to medicines including family planning services

\begin{tabular}{|c|c|}
\hline How often do you go to the following as sources of treatment for illness? (never, rarely, occasionally, often, very often) & $\begin{array}{l}\text { Mean rating (out of } \\
\text { 5-point Likert scale) }\end{array}$ \\
\hline PPMVs & 3.4 \\
\hline Hospitals & 2.5 \\
\hline Health centres & 2.4 \\
\hline Herbalists & 1.8 \\
\hline Spiritualists & 1.6 \\
\hline \multicolumn{2}{|l|}{ To what extent do you agree with the following (strongly disagree, disagree, unsure, agree, strongly agree) } \\
\hline (i) PPMVs are the first and often the only point of call for health care services in this rural area & 3.7 \\
\hline (ii) PPMVs are easily accessible to the rural dwellers & 4.2 \\
\hline (iii) The medicines and drugs sold by the PPMVs are cheaper and more affordable than in hospitals and pharmacies & 3.7 \\
\hline (iv) Many PPMVs in this locality sell low quality, expired or sub-standard drug to the rural dwellers & 3.2 \\
\hline (v) Many of the PPMVs in this locality do not have the prerequisite training to operate PPMV shops & 3.3 \\
\hline (vi) Sale of medicines without prescription is rampant in this locality & 3.8 \\
\hline (vii) Dispensing medicines without prescription should not be encouraged & 4.0 \\
\hline (viii) Medicines/drugs availability without restriction and control to public is big problem & 3.9 \\
\hline $\begin{array}{l}\text { (ix) PPMV shop owners and operators generally have low health knowledge about proper treatment for common illnesses, such } \\
\text { as malaria and diarrhoea and poor health treatment practices }\end{array}$ & 3.1 \\
\hline \multicolumn{2}{|l|}{ How often do you carry out the following? (never, rarely, occasionally, frequently, very frequently) } \\
\hline (i) How often do you buy and use family planning products like condoms from PPMVs & 1.7 \\
\hline (ii) How often do you buy and use family planning products like oral contraceptives from PPMVs & 1.4 \\
\hline (iii) How often do you buy and use family planning products like contraceptives injections & 1.4 \\
\hline (iv) How often do you buy and use sexually transmitted infections drugs/medicines from PPMVs & 1.8 \\
\hline $\begin{array}{l}\text { (v) How often have you being referred to hospitals by PPMVs for family planning related/reproductive health problems to } \\
\text { hospitals? }\end{array}$ & 1.4 \\
\hline (vi) How often have you being educated or advised by PPMVs on the options and usage of family planning products? & 1.8 \\
\hline (vii) How often do access abortion/post-abortion care services from PPMVs? (For females only) & 1.4 \\
\hline
\end{tabular}

were frequently the first to identify illness symptoms [46]. Most of these mothers had a minimum of secondary schooling qualification. This agrees with a study conducted in Cross River and Bauchi States of Nigeria where they noted that mothers who have not attended school have lower rates of appropriate care seeking when compared to those that have attended school [47]. Appropriate care seeking involves identifying the need to take the child for treatment outside the home, ensuring that the care is not delayed and that the child is taken to appropriate health facility or provider [48].

Drug advice on the treatment of coughs and colds and on antibiotic use were obtained from patent medicine vendors and from health workers. This work agrees with the study by Prach and co-workers [36] where they noted that in addition to selling drugs patent medicine vendors can be a source of advice about illness and drug therapy [49]). The work done by Abdu-Aguye [50] showed that patent medicine vendors knowledge about antibiotics is moderate and needs to be enhanced by further training to ensure that they do not transfer wrong knowledge to their clients [50].
The respondents self-reported perceived efficacy of antibiotics was very high, with up to $90.8 \%$ reporting that their children got well after antibiotic treatment. The awareness of antibiotics could have been made possible by the information provided to them during counselling by PPMVs and health workers. This gives credence to the findings of Ibeneme and colleagues [29] where they noted that fewer than half of the mothers who resorted to PPMVs for treatment of childhood febrile conditions perceived that their child had fully recovered. However, in this study a few of the mothers noted that the sickness persisted after treatment. Okeke and his colleagues [39] noted that this persistence could be due to misdiagnosis and/or mismanagement of the health condition.

Interestingly, among the young people, our finding showed that only $25.5 \%$ of the respondents have ever purchased family planning products. Furthermore, the MNR for the questions related to the frequency of buying and using family planning products like condoms, oral contraceptives and contraceptives injections was very low, ranging from 1.4 to 1.7 out of 5-point Likert scale. The low rate of use of family planning commodities by youths is also reported in previous studies [51-53]. Nigeria, is 
Table 6 Proportion of respondent youths that purchased various drug types from PPMVs and barriers/enablers to the use of PPMVs services

\begin{tabular}{|c|c|c|}
\hline Variable & $\begin{array}{l}\text { Frequency } \\
(n=146)\end{array}$ & Percentage (\%) \\
\hline \multicolumn{3}{|l|}{ Drug group name } \\
\hline Antimalarial & 134 & 95.0 \\
\hline Analgesics & 128 & 87.7 \\
\hline Antibiotics & 117 & 81.3 \\
\hline Antiseptics & 115 & 72.4 \\
\hline Haematinics & 95 & 66.9 \\
\hline Oral rehydration solution & 91 & 62.8 \\
\hline Herbal mixture & 80 & 54.8 \\
\hline Antitussives & 79 & 55.6 \\
\hline Anthelminthic & 77 & 54.6 \\
\hline Medical consumables & 71 & 49.3 \\
\hline Zinc tablets & 69 & 47.6 \\
\hline Antacids & 64 & 44.8 \\
\hline Intravenous fluids & 60 & 41.4 \\
\hline Parenteral drugs & 55 & 38.5 \\
\hline Antihistamines & 55 & 38.2 \\
\hline Family planning commodities & 37 & 25.5 \\
\hline Anxiolytics & 26 & 18.6 \\
\hline Antipsychotics & 18 & 12.4 \\
\hline Antihypertensive & 17 & 12.0 \\
\hline Antidiabetics & 11 & 7.6 \\
\hline \multicolumn{3}{|c|}{ Enablers and barriers to the use of PPMVs by the respondents } \\
\hline \multicolumn{3}{|c|}{ Enablers } \\
\hline Closeness to the people & 87 & 65.2 \\
\hline Cheap drugs & 66 & 44.2 \\
\hline Good response to care & 16 & 11.0 \\
\hline Good rapport with the people & 13 & 8.9 \\
\hline No delay in accessing care & 10 & 6.8 \\
\hline Access to credit facility & 5 & 3.4 \\
\hline \multicolumn{3}{|l|}{ Barriers } \\
\hline Sale of substandard/expired drugs & 52 & 35.6 \\
\hline Lack of training & 44 & 30.1 \\
\hline Low educational qualification & 28 & 19.2 \\
\hline Fear of side effects & 11 & 7.5 \\
\hline Lack of supervision & 9 & 6.2 \\
\hline Lack of experience & 6 & 4.1 \\
\hline
\end{tabular}

among the countries globally with highest rates of adolescent fertility at 109 births per 1000 girls aged 15-19 per year, and yet also has one of the lowest rates of use of modern contraception in adolescents [54]. In Nigeria, 98.8\% of married adolescent girls and $50.3 \%$ of unmarried sexually active adolescent girls do not use a modern contraceptive method [55]. Among the reported barriers to adolescent contraceptive use are lack of knowledge of services, cost, shyness and community stigma about
Table 7 Summary of response from the youths on issues concerning access to medicines and health care services by PPMVs

\begin{tabular}{|c|c|c|}
\hline Parameter assessed & $\begin{array}{l}\text { Frequency } \\
(n=146)\end{array}$ & Percent (\%) \\
\hline \multicolumn{3}{|l|}{ Common illness } \\
\hline Malaria & 117 & 71.3 \\
\hline Headaches & 76 & 51.2 \\
\hline Stomach ache & 45 & 30.8 \\
\hline Cough/cold & 36 & 24.7 \\
\hline Typhoid & 32 & 21.9 \\
\hline Body pain/weakness & 29 & 19.9 \\
\hline Fever & 16 & 11.0 \\
\hline \multicolumn{3}{|c|}{ Source of advice/information on medicines } \\
\hline Parents & 68 & 42.2 \\
\hline PPMVs & 56 & 38.4 \\
\hline Friends & 33 & 22.6 \\
\hline Other health workers & 30 & 20.5 \\
\hline Doctors & 18 & 12.3 \\
\hline Relatives & 11 & 7.5 \\
\hline Media & 10 & 6.8 \\
\hline \multicolumn{3}{|c|}{ Commonly used medicines } \\
\hline Antimalarial & 60 & 41.1 \\
\hline Paracetamol & 56 & 38.4 \\
\hline Analgesics & 53 & 36.3 \\
\hline Antibiotics & 50 & 34.2 \\
\hline Contraceptives & 23 & 15.8 \\
\hline Tramadol & 22 & 15.1 \\
\hline Vitamins & 18 & 12.3 \\
\hline \multicolumn{3}{|c|}{ Outcome after accessing care from PPMVs } \\
\hline Got well & 99 & 67.8 \\
\hline Got a little better & 38 & 26.0 \\
\hline No improvement & 5 & 3.4 \\
\hline Got worse & 4 & 2.7 \\
\hline
\end{tabular}

sexual activity and disapproving attitudes from providers [56-58]. In Nigeria, adolescent sexual and reproductive health is affected by cultural, religious, legal, political and economic contexts [59].

A number of Nigeria health policies and other initiatives aimed at reducing disease burden in the country incorporate PPMVs as primary health care service providers [60]. As shown in this study, the PPMVs sell both antibiotics and contraceptives they are legally unauthorized to sell. Given their geographic spread, market share, and accessibility, PPMVs represent an important and often the only opportunity for access to primary health care services in most rural communities in Nigeria [7]. Consequently, despite regulations, it is common for PPMVs in Nigeria to provide services they are legally prohibited from offering, for which they have not received any training, including injectable contraceptives 
and dispensing antibiotics [7]. One of the main factors responsible for this is the high client patronage for these types of medicines, of which the PPMVs may be the only available source. Available report indicated that $11 \%$ of women who use injectable contraceptives noted getting their injectables from PPMVs [51]. While the majority of PPMV shops stock family planning commodities, few have received training on family planning methods, and therefore provide inadequate or often misleading counsel to their customers on family planning options or usage, and are less likely than other family planning providers to inform customers about method options or side effects $[10,51-53]$.

It has been argued that given the growing importance of family planning in Nigeria, contraceptives, including injectable contraceptives, should be added to the list of drugs that PPMVs are expected to stock in their shops [51]. There are calls for studies with training components for PMPVs on how to counsel clients about injectables, screen clients for eligibility, sell the method and administer injections with close supervision and monitoring by the NAPPMED and the FMOH [51-53]. Incorporating PPMVs into the health system may lead to increased use of family planning services among the target population of rural adolescents and the role of this towards UHC. This would require policy change and collaboration at the national level.

\section{The limitation of study}

The use of a quantitative cross-sectional technique in this study was a main limitation. This is because the technique does not adequately provide context of study situation as noted in a study in Nigeria which used this technique [22]. The use of descriptive study method (qualitative or causal relationship based on a longitudinal technique) is recommended in future studies. Another limitation to this study was the use of self-assessment technique. This technique has been reported to possess some merits especially in this type of study, but its main weakness lies in the fact that it is very difficult for a respondent to be able to critically recognize and understand his or her own gap in skills and knowledge [61]. Self-assessments have also been described as subject to self-esteem bias, may be unreliable, and are difficult to validate [62].

\section{Conclusion and policy recommendations}

The PPMVs have a large population, are in close proximity to the rural and underserved areas of Nigeria and have been included in the integrated community case management (iCCM) team. There is need to enhance their capacity through training in the proper dosage and duration of antibiotics as well as drug advice and information on proper treatment of childhood cough with antibiotics. It is also essential for the revisitation of existing policy for a possible review to expand the scope of the services the PPMVs can render. Most antibiotics used by nursing mothers to treat their children's cough and cold were obtained from patent drug shops. These drugs also provided the treatment relief needed. More studies are encouraged in this wise to enable a change in policy regarding the types of antibiotics allowed the PPMVs to handle as well as improved monitoring and supervision channels.

This study has provided context-specific evidence on the access to medicines including family planning commodities provided by PPMVs among young people. It is obvious that there is no complete adherence to the National Drug Policy guidelines/regulatory framework on family planning services and antibiotic dispensing by the PPMVs, largely because they are the only source of these medicines in the rural areas. The study therefore makes a case for the possibility of the introduction of a training mechanism for the PPMVs that will equip them to legally dispense contraceptives and antibiotics. The study advocates for a possible policy change since these regulations may be constituting barriers to good practice. More studies are needed to determine the safety and feasibility of this practice.

\section{Acknowledgements \\ We would like to thank all the nursing mothers who participated in this research. We would like to thank all the PPMVs and the leadership of NAPPMED for their participation in this research.}

\section{About this supplement}

This article has been published as part of Journal of Pharmaceutical Policy and Practice Volume 14, Supplement 1 2021: Strengthening health systems: The Role of Drug Shops. The full contents of the supplement are available at https://joppp.biomedcentral.com/articles/supplements/volume-14-suppl ement-1.

\section{Authors' contributions}

Conception and design: CJU, BIU. Acquisition of data: CJU, CAN, IO, AU, KIO, OEU. Analysis and interpretation of data: CJU, BIU, KIO, OEU. Drafting of the manuscript: CJU, IO, AU. Critical revision of the manuscript for important intellectual content: CJU, CAN, BIU, IO, AU. Administrative, technical, or material support: CJU, BIU. All authors read and approved the final manuscript.

\section{Funding}

This research was supported by funding from the Alliance for Health Policy and Systems Research through a grant from USAID. The Alliance is supported through both core funding as well as project specifc designated funds. The full list of Alliance donors is available here: https:/www.who.int/alliancehpsr/ partners/en/.

\section{Declarations}

Competing interests

The authors declare that they have no competing interests.

Received: 4 March 2021 Accepted: 7 June 2021

Published: 16 November 2021 


\section{References}

1. National Population Commission (NPC) [Nigeria] and ICF. Nigeria demographic and health survey 2018. Abuja: NPC and ICF. 2019. https://dhspr ogram.com/pubs/pdf/FR359/FR359.pdf.

2. Okoli C, Hajizadeh M, Rahman MM, Khanam R. Geographical and socioeconomic inequalities in the utilization of maternal healthcare services in Nigeria: 2003-2017. BMC Health Serv Res. 2020;20(1):849.

3. Uneke CJ, Sombie I, Uro-Chukwu HC, Johnson E. Developing equityfocused interventions for maternal and child health in Nigeria: an evidence synthesis for policy, based on equitable impact sensitive tool (EQUIST). Pan Afr Med J. 2019;25(34):158.

4. WHO. Levels and trends in child mortality 2012. 2012. Accessed 19 July 2020.

5. World Bank. Population, total—Nigeria. The World Bank Group. 2020. https://data.worldbank.org/indicator/SP.POP.TOTL?locations=NG.

6. United Nations Population Fund. Adolescents and youth dashboardNigeria. United Nations Population Fund. 2020. https://www.unfpa.org/ data/adolescent-youth/NG.

7. Desmennu AT, Titiloye MA, Owoaje ET. Behavioural risk factors for sexually transmitted infections and health seeking behaviour of street youths in Ibadan, Nigeria. Afr Health Sci. 2018;18(1):180-7.

8. National Population Commission (NPC) [Nigeria] and ICF International. Nigeria demographic and health survey 2013. Abuja: NPC and ICF International; 2014.

9. Ebonyi State Ministry of Health. 2018 updated Ebonyi SMOH Basic Statistics. Department of Health Information Management Systems. 2018.

10. Liu J, Beyeler N, Prach LM, Sieverding M, Isiguzo C, Nwokolo E, Anyanti J. The landscape of patent and proprietary medicine vendors in 16 states of Nigeria. Abuja: Society for Family Health; 2015.

11. Okonkwo AD, Okonkwo UP. Patent medicine vendors, community pharmacists and STI management in Abuja, Nigeria. Afr Health Sci. 2010;10(3):253-65.

12. Barnes J, Chandani T, Feeley R. Nigeria private sector health assessment. Bethesda: Private Sector Partnerships-One project, Abt Associates Inc. 2008.

13. Africa Health Workforce Observatory [AHWO]. Human resources for health country profile: Nigeria. Geneva: World Health Organization; 2008.

14. National Bureau of Statistics, UNICEF, UNFPA. Nigeria multiple indicator cluster survey 2011: main report. Abuja: NBS, UNICEF and UNFPA; 2013. https://www.unicef.org/nigeria/reports/nigeria-multiple-indicator-clust er-survey-mics-2011.

15. Onwujekwe $\mathrm{O}$, Hanson $\mathrm{K}$, Uzochukwu B. Do poor people use poor quality providers? Evidence from the treatment of presumptive malaria in Nigeria. Trop Med Int Health. 2011;16:1087-98.

16. Nigerian Federal Ministry of Health. Essential medicine list, 5 th Revision. Abuja, Nigeria; 2010. http://digicollection.org/hss/en/m/abstract/Js190 $18 \mathrm{en} /$.

17. National Primary Health Care Development Agency. Draft essential childhood medicines scale-up plan. Abuja: Federal Ministry of Health; 2011. https://www.childhealthtaskforce.org/sites/default/files/2019-05/ Essential\%20Childhood\%20Medicines\%20Scale-Up\%20Plan\%28Fed eral\%20Ministry\%20of\%20Health\%2CNational\%20Primary\%20Health\% 20Care\%20Development\%20Agency\%2C\%202012\%29.pdf.

18. Federal Ministry of Health, Nigeria. National guideline for the implementation of integrated community case management of childhood illness in Nigeria. Abuja, Nigeria; 2013. https://pdf.usaid.gov/pdf_docs/PA00TGG9. pdf.

19. Federal Republic of Nigeria. National antimalarial treatment policy. Abuja: Federal Ministry of Health; 2005. http://digicollection.org/hss/docum ents/s18401en/s18401en.pdf.

20. Tsang S, Royse CF, Terkawi AS. Guidelines for developing, translating, and validating a questionnaire in perioperative and pain medicine. Saudi J Anaesth. 2017;11(Suppl 1):S80-9.

21. Johnson NA, Lavis JN. Procedures manual for the "evaluating knowledgetranslation platforms in low- and middle-income countries" study. Hamilton: McMaster University Program in Policy Decision-Making; 2009.

22. Uneke CJ, Sombie I, Keita N, Lokossou V, Johnson E, Ongolo-Zogo P. An assessment of national maternal and child health policy-makers' knowledge and capacity for evidence-informed policy-making in Nigeria. Int J Health Policy Manag. 2017;6(6):309-16.
23. Durowade KA, Bolarinwa OA, Fenega CJ, Akande TM. Operations and roles of patent and proprietary medicine vendors in selected rural communities in Edu Local Government Area, Kwara State, North-Central Nigeria. J Community Med Prim Healthc. 2018;30:2.

24. Iheoma C, Daini B, Lawal S, ljaiya M, Fajemisin W. Impact of patent and proprietary medicine vendors training on the delivery of malaria, diarrhoea and family planning services in Nigeria. Open Access Lib J. 2016:3:1-10.

25. Beyeler N, Liu J, Sieverding M. A systematic review of the role of proprietary and patent medicine vendors in healthcare provision in Nigeria. PLOS ONE. 2015;10(1):e0117165.

26. Sieverding M, Beyeler N. Integrating informal providers into a peoplecentered health system approach: qualitative evidence from local health systems in rural Nigeria. BMC Health Serv Res. 2016;16(1):526.

27. Okumagba M. Improving access to health care in rural communities by re-orienting and integrating patent medicine sellers into primary health care service delivery in Nigeria. S Am J Pub Health. 2015;3(2):1-18.

28. Jill Ans. Perceptions, management and barriers to care-seeking for childhood diarrhea, malaria, and pneumonia: Uganda, Kenya, Nigeria, Ethiopia, Niger, Durham, North Carolina USA. 15 February 2012.

29. Ibeneme GC, Nwaneri AC, Ibeneme SC, Ezenduka P, Strüver V, Fortwengel $\mathrm{G}$, Okoye IJ. Mothers' perception of recovery and satisfaction with patent medicine dealers treatment of childhood febrile conditions in rural communities. Malar J. 2016;15:336.

30. Abdu-aguye SN, Shehu A, Ahmad UI. Management of musculoskeletal pain in retail drug outlets in rural community: a descriptive study. Pharm Pract. 2017:15(1):873

31. Ajayi IO, Falade CO, Adeniyi JD, Bolaji MO. The role of patent medicine sellers in home management of childhood malaria: a situational analysis of experience in rural Nigeria. Int Q Community Health Educ. 2002:21:271-81.

32. Umeokonkwo CD, Aniebue PN, Onoka CA, Adaoha AP, Muawiyyah BS, Ogbonnaya L. Patients' satisfaction with HIV and AIDS in Anambra State Nigeria. PLoS ONE. 2018;13(10):e0206499.

33. Ogaji DS, Mezie-Okoye MM. Waiting time and patient satisfaction: Survey of patients seeking care at the general outpatient clinic of the University of Port Harcourt Teaching Hospital. Port Harcourt Med J. 2017;11:148-55.

34. Brieger WR, Osamor PE, Salami KK, Oladepo O, Otusanya SA. Interactions between patent medicine vendors and customers in urban and rural Nigeria. Health Policy Plan. 2004;19:177-82.

35. Idowu OA, Apalara SB, Lasisi AA. Assessment of quality of quality of chloroquine tablets sold by drug vendors in Abeokuta, Nigeria. Tanzan J Health Res. 2006:8:45-8.

36. Oladepo O, Brieger W, Adeoye B, Lawal B, Peters DH. Awareness of antimalarial policy and malaria treatment practices of patent medicine vendors in three Nigerian states. Afr J Med Sci. 2011;40:345-52.

37. Obitte NC, Chukwu A, Odimegwu DC, Nwoke VC. Survey of drug storage practice in homes, hospitals and patent medicine stores in Nsukka Nigeria. Sci Res Essay. 2009:4:1354-9.

38. Onwujekwe O, Kaur H, Dike N, Shu E, Uzochukwu B, Hanson K, et al. Quality of anti-malarial drugs provided by public and private healthcare providers in South-East Nigeria. Malar J. 2009;8:22.

39. Okeke TA, Uzochukwu BSC, Okafor HU. An in-depth study of patent medicine sellers' perspectives on malaria in a rural Nigerian community. Malar J. 2006:5:97.

40. Egboh A. Pharmacy laws and practice in Nigeria. Ikeja: Lieramed Publications; 1984.

41. Oyeyemi AS, Ogunnowo BE, Odukoya OO. Patent medicine vendors in rural areas of Lagos Nigeria: compliance with regulatory guidelines and implications for malaria control. Trop J Pharm Res. 2014;13(1):163.

42. Firima E, Forsberg BC. Knowledge and recommendation of oral rehydration solution and zinc for management of childhood diarrhea among patent and proprietary medicine vendors in Port-Harcourt, Nigeria. J Glob Health Rep. 2020:4:e202013.

43. Akinyandenu $\mathrm{O}$, Akinyadenu A. Irrational use and non-prescription sale of antibiotics in Nigeria: a need for change. J Sci Innov Res. 2014;3(2):251-7.

44. World Health Organization. The role of the pharmacist in self-care medication. Geneva:WHO; 1998. http://whqlibdoc.who.int/hq/1998/who DAP_98.13pdf.

45. Indalo AA. Antibiotic sale behavior in Nairobi: a contributing factor to antimicrobial drug resistance. East Afr Med J. 1997;74:171-3. 
46. Amy AE, Seddou D, Sidy T, Dalglish SL, Peter JW. Household roles and care-seeking behaviours in response to severe childhood illness in Mali. J Biosoc Sci. 2013;45:743-59.

47. Odu BP, Mitchell S, Isa H, Ugot I, Yusuf R, Cockcroft A, et al. Equity and seeking treatment for young children with fever in Nigeria: a crosssectional study in Cross-river and Bauchi States. Infect Dis Poverty. 2015;4(1):1.

48. Ogundele OA, Ogundele T, Olajide OS, Agunbiade OI. Effect of community integrated management of childhood illness on mothers' healthcare seeking behavior and home management of childhood illness in Ile-Ife, south-west Nigeria: a household survey. S Afr J Child Health. 2016;10(1):16-9.

49. Prach LM, Treleaven E, Isiguzo C, Liu J. Care-seeking at patent medicine vendors in Nigeria. BMC Health Serv Res. 2015;15:231.

50. Abdu-Aguye SN, Yunusa AN, Maaji HU, Labaran KS, Yusuf H. How much do patent medicine vendors really know about antibiotics? 14th Annual national conference \& scientific meeting of the Nigeria Association of Pharmacists in Academia (NAPA) at: Sagamu, Ogun State, Nigeria. 2016 https://www.researchgate.net/publication/307583868_HOW_MUCH_ DO_PATENT_MEDICINE_VENDORS_REALLY_KNOW_ABOUT_ANTIBIOTICS.

51. FHI360. Research and recommendations on the delivery of injectable contraceptive services by patent medicine vendors in rural Nigeria. 2013.

52. Hebert LE, Schwandt HM, Boulay M, Skinner J. Family planning providers' perspectives on family planning service delivery in Ibadan and Kaduna, Nigeria: a qualitative study. J Fam Plann Reprod Health Care. 2013;39:29-35.

53. Ujuju C, Adebayo SB, Anyanti J, Oluigbo O, Muhammad F, Ankomah A. An assessment of the quality of advice provided by patent medicine vendors to users of oral contraceptive pills in urban Nigeria. J Multidiscip Healthc. 2014;7:163-71.

54. Family Planning 2020. Family Planning 2020: accelerating progress, strategy for 2016-2020. http://www.familyplanning2020.org/microsite/strat egy.
55. The DHS program. Nigeria demographic and health survey. 2013. http:// dhsprogram.com/publications/publication-fr293-dhs-final-reports.cfm.

56. Patton GC, Sawyer SM, Santelli JS, et al. Our future: a Lancet commission on adolescent health and wellbeing. Lancet. 2016;387:2423-78.

57. Owonikoko KM, Oyelade FO, Oke OF, Adeyemi AS. Contraception usage among young adult men of a Nigerian university. Int J Adolesc Med Health. 2018;31(1):1.

58. Onasoga OA, Afolayan JA, Asamabiriowei TF, Jibril UN, Imam AA. Adolescents' knowledge, attitude and utilization of emergency contraceptive pills in Nigeria's Niger Delta Region. Int J MCH AIDS. 2016;5(1):53-60.

59. Atchison CJ, Mulhern E, Kapiga S, Nsanya MK, Crawford EE, Mussa M, Bottomley C, Hargreaves JR, Doyle AM. Evaluating the impact of an intervention to increase uptake of modern contraceptives among adolescent girls (15-19 years) in Nigeria, Ethiopia and Tanzania: the Adolescents 360 quasi-experimental study protocol. BMJ Open. 2018;8(5):e021834.

60. Federal Ministry of Health, National Drug Policy. 1st revised ed., Federal Ministry of Health Production, Nigeria. 2005. http://digicollection.org/ hss/en/m/abstract/Js16450e/.

61. Deans F, Ademokun A. Investigating capacity to use evidence. http:// www.inasp.info/uploads/filer_public/2013/07/04/investigating_capac ity_to_use_evidence.pdf. Accessed 21 May 2020.

62. Haahr JH, Shapiro H, Sørensen S. Defining a strategy for the direct assessment of skills. Danish Technological Institute; 2004. http://www.pedz. uni-mannheim.de/daten/edz-b/gdbk/04/defining_strategy_final.pdf. Accessed 30 July 2020.

\section{Publisher's Note}

Springer Nature remains neutral with regard to jurisdictional claims in published maps and institutional affiliations.
Ready to submit your research? Choose BMC and benefit from:

- fast, convenient online submission

- thorough peer review by experienced researchers in your field

- rapid publication on acceptance

- support for research data, including large and complex data types

- gold Open Access which fosters wider collaboration and increased citations

- maximum visibility for your research: over $100 \mathrm{M}$ website views per year

At BMC, research is always in progress.

Learn more biomedcentral.com/submissions 